\title{
Transcatheter Treatment of Coarctation of Aorta and Dually Connected Anomalous Vertical Pulmonary Vein as a Combined Procedure
}

\author{
Atiq Mehnaz ${ }^{1 *}$, Younis Muhammad Kamran ${ }^{1}$ and Amanullah Muneer ${ }^{2}$ \\ ${ }^{1}$ Department of Pediatric Cardiology, Pakistan \\ ${ }^{2}$ Department of Cardiac surgery, Pakistan
}

*Corresponding author: Atiq Mehnaz, Department of Pediatric Cardiology, Liaquat National Hospital and Medical Center, National Stadium Road, Karachi, Pakistan

\author{
ARTICLE INFO \\ Received: 蔧 July 08, 2019 \\ Published: July 23, 2019 \\ Citation: Atiq Mehnaz. Transcatheter \\ Treatment of Coarctation of Aorta and \\ Dually Connected Anomalous Vertical \\ Pulmonary Vein as a Combined Proce- \\ dure. Biomed J Sci \& Tech Res 19(5)- \\ 2019. BJSTR. MS.ID.003372.
}

\begin{abstract}
Partial anomalous pulmonary venous connection may be an isolated anomay but is usually associated with an atrial septal defect. We report a case in which this anomaly was associated with coarctation of aorta. Since the partially anomalous veins had dual connection with left atrium and innominate vein, we treated both the coarctation of aorta and the partial veinous connection by transcatheter technique as a combined procedure
\end{abstract}

Keywords: Coarctation of Aorta; Partial Anomalous Pulmonary Venous Connection; Combined Transcatheter Interventions

Abbreviations: CT: Computerized Tomographic; PAPVC: Partial Anomalous Pulmonary Venous Connection; CP: Cheatham Platinum

\section{Introduction}

Partial anomalous pulmonary venous connection (PAPVC) occurs due to failure of one or more pulmonary veins to connect with left atrium during fetal development. More frequent is presence of single anomalous pulmonary vein, an entity which can be missed clinically as well as on echocardiography [1]. PAPVC is frequently associated with atrial septal defects, and rarely with other congenital cardiac abnormalities [2]. We describe transcatheter treatment of the coarctation of aorta and occlusion of the dually connected partial anomalous pulmonary venous connection as a combined procedure without complications.

\section{Case Report}

Thirteen-year-old girl presented with headache and exertional dyspnea. She had diminished pulses in the lower limbs with an upper limb blood pressure of 155/85 mmHg. She had no stigmata of Turner's syndrome. The precordium was heaving, first heart sound was loud, second heart sound widely split with a soft systolic murmur at the left upper sternal edge. With a suspicion of coarctation of aorta and atrial septal defect an echocardiogram was performed which showed a discrete juxta ductal coarctation of aorta, right ventricular enlargement and an anomalous left upper pulmonary vein to innominate vein. All 4 pulmonary veins were also identified to connect to the left atrium and there was no atrial septal defect. A computerized tomographic (CT) scan was done at another facility for coarctation of aorta did not focus on the pulmonary venous anomaly. She was planned to have the coarctation treated with covered stent and if found to be hemodynamically significant, the anomalous veins would be treated surgically at a later date. Cardiac catheterization and angiography performed under general anesthesia showed discrete juxtaductal coarctation, narrowest segment measuring $3.3 \mathrm{~mm}$ and pressure gradient across the coarctation was $40 \mathrm{mmHg}$. Both femoral venous accesses were obtained. Oxygen saturations were $99 \%$ in the verticle vein, $93 \%$ in the innominate vein and pulmonary artery, and $82 \%$ in high superior vena cava.

$\mathrm{QP} / \mathrm{QS}$ ratio was 2.8. A selective left pulmonary arteriogram showed left veins joining to form a confluence that connected to left atrium and a large vertical venous channel connected the 
confluence of left pulmonary veins to innominate vein (Figure 1). Right pulmonary arteriogram showed normal right pulmonary venous connection to left atrium. Coarctation of aorta was treated with 39mm X 8 zig covered Cheatham Platinum (CP) stent (NuMED Corp, Hopkinton, NJ) mounted over a $12 \mathrm{~mm}$ X $4 \mathrm{~cm} \mathrm{Z} \mathrm{Med} \mathrm{balloon}$ (NuMED Inc. USA) was deployed reducing the gradient to $5 \mathrm{mmHg}$. Vertical vein measured $12 \mathrm{~mm}$ in diameter. Balloon occlusion of the vertical vein was done with the same balloon $12 \mathrm{X} 4 \mathrm{~mm}$ $\mathrm{Z}$ Med balloon and a left pulmonary arteriogram done showed unobstructed left pulmonary venous drainageto left atrium (Figure 2 ). The vertical vein was occluded with $20 \mathrm{~mm}$ Amplatzer vascular plug II (St Jude Medical, Plymouth, MN), deployed through $10 \mathrm{Fr}$ Mullin sheath (Mullin, Medtronic, Minneapolis, MN) with the proximal disc in the innominate vein. The device was released after re-confirming unobstructed pulmonary venous return (Figure 3). The final innominate venogram showed good position of the device(Figure 4). A follow up three months later has shown no flow across the device on echocardiogram and good relief of aortic coarctation, pressure gradients being $18 \mathrm{mmHg}$.

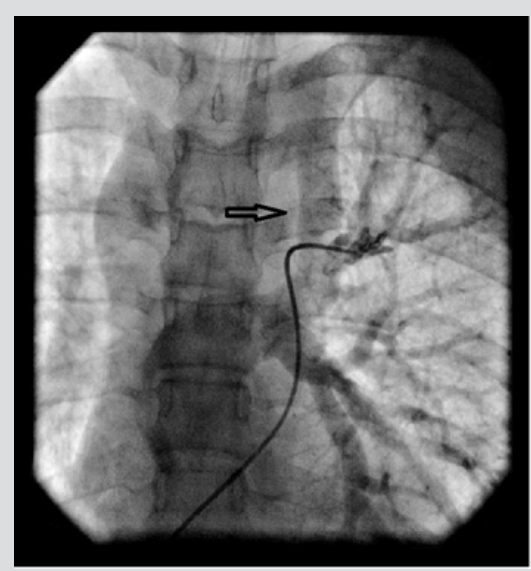

Figure 1: Left pulmonary arteriogram showing the vertical vein (arrow) in levophase before stent placement across coarctation of aorta.

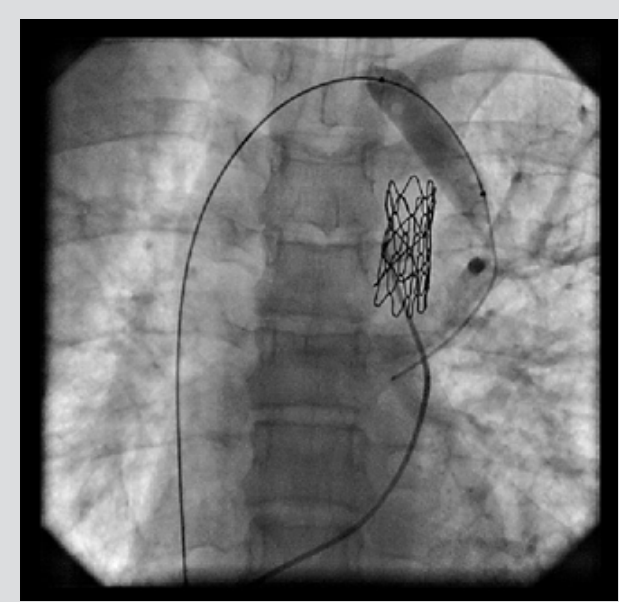

Figure 2: Balloon occlusion of the vertical vein with left pulmonary angiogram in levophase showing left pulmonaryvenous connection (arrow). Stent seen across coarctation of aorta.

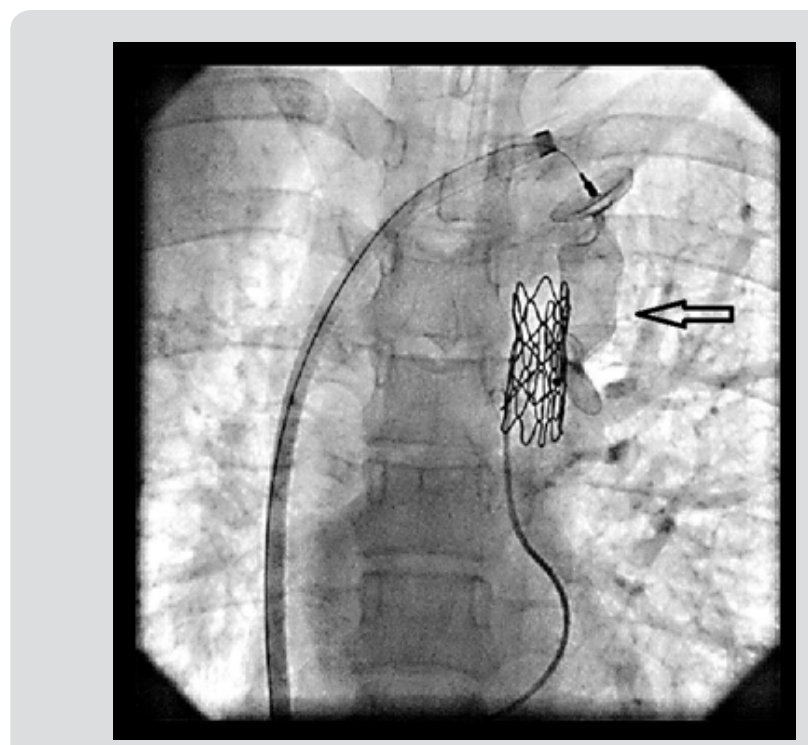

Figure 3: Amplatzer vascular plug II (arrow) being deployed in the vertical vein.

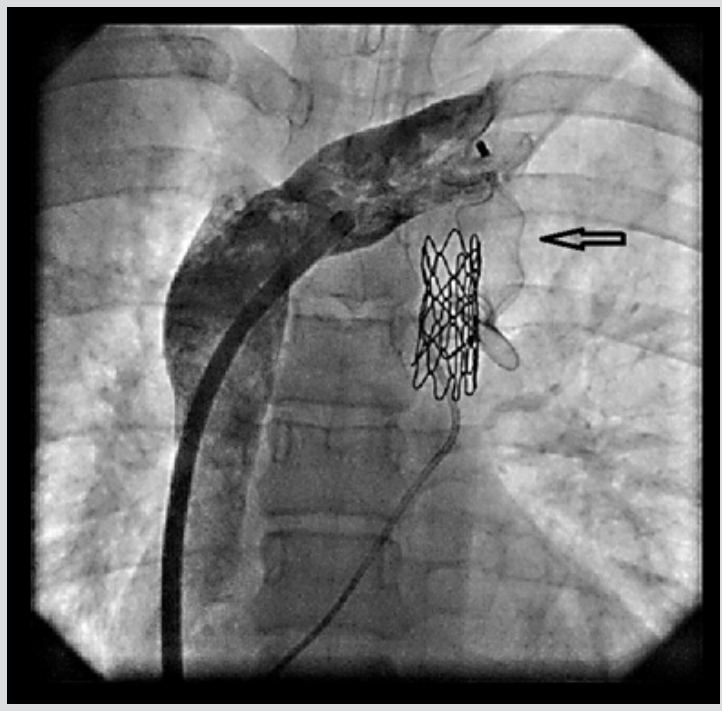

Figure 4: Innominate venogram showing well seated Amplatzer vascular plug II (arrow) in the vertical vein.

\section{Discussion}

The development of the pulmonary veins in the fetus is a complicated process. PAPVC occurs when at least one (but not all) of the pulmonary veins connects to the right atrium instead of left, directly or indirectly through one or more of the draining systemic veins [3]. It has been reported in $0.6-0.7 \%$ of autopsies but certainly less reported clinically [4]. PAPVC occurs more frequently on the right side [2]. A modified classification of PAPVC has been proposed by Alsoufi [4]. Type 1 is connection of right PAPVC to superior vena cava, type 2 is their connection to right atrium, type 3 is right PAPVC to inferior vena cava (scimitar syndrome), type 4 is connection of left PAPVC to innominate vein and type 5 is bilateral PAPVC. This classification does not include dual connection of veins. Embryological basis for occurrence of coarctation with PAPVC is unclear. It has been described in patients with Turners syndrome [5]. 
Kakouros have described a case of coarctation of aorta and an incidental finding of an aberrant left pulmonary vein that crossed over to join the right pulmonary vein to open into left atrium, but in strict context, was not an anomalous drainage [6]. Total anomalous pulmonary venous connection of intracardiac variety has been reported with coarctation of aorta [7]. Mamas [3] described transcatheter treatment of coarctation of aorta and closure of a vertical vein in a patient with doubly connected PAPVC, similar to our patient. However, they staged the procedure addressing the anomalous pulmonary vein closure during the second stage. To our knowledge this is the first procedure reported which has addressed the coarctation of aorta and occlusion of the vertical vein as a combined procedure. Historically, multiple cardiac pathologies, such as in the present case, would be treated with surgery. But improved technics have made it possible to address multiple defects by transcatheter techniques at the same time. In our patient we stented the coarctation first and then addressed the vertical vein, which was possible due to dual pulmonary venous connection.

\section{References}

1 Magalhães SP, Moreno N, Loureiro M, França M, Reis F, et al. (2016) Aomalous pulmonary venous connection: An underestimated entity. Rev Port Cardiolo 2016; 3(12): 697:e1-697-e6.

\section{ISSN: 2574-1241}

DOI: 10.26717/BJSTR.2019.19.003372

Atiq Mehnaz. Biomed J Sci \& Tech Res

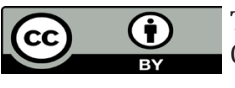

This work is licensed under Creative Commons Attribution 4.0 License

Submission Link: https://biomedres.us/submit-manuscript.php
2 Luciano D, Laux D, Boudjemline Y, Hascoët S, Lusson JR, et al. (2013) Transcatheter therapy in partially abnormal pulmonary venous return with additional drainage to the left atrium. Int Journal Cardiol 170(2): 221-226.

3 Mamas MA, Clarke B, Mahadevan VS (2010) Percutaneous treatment of dual pulmonary venous drainage and coarctation of the aorta in a single patient. Exp Clin Cardiol 15(1): 11-13.

4 Alsoufi B, Cai S, Van Arsdell GS, Williams WG, Caldarone CA, et al. (2007) Outcomes after surgical treatment of children with partial anomalous pulmonary venous connection. Ann Thorac Surg 84(6): 2020-2026.

5 Van Wassenaer AG, Lubbers LJ, Losekoot G (1998) Partial abnormal pulmonary venous return in Turner syndrome. Eur J Pediatr 148(2): 101-103.

6 Kakouros N, Giles J, Walker D (2008) Anomalous unilateral pulmonary vein in a patient with aortic coarctation. J Cardiovasc Computed Tomography 2(4): 274-275.

7 Doksöz O, Guven B, Demirpençe S, Özdemir R, Meșe T, et al. (2014) Coarctation of the aorta with infracardiac total anomalous pulmonary venous drainage: a rare combination. Ann ThoracCardiovasc Surg 20: 778-780.

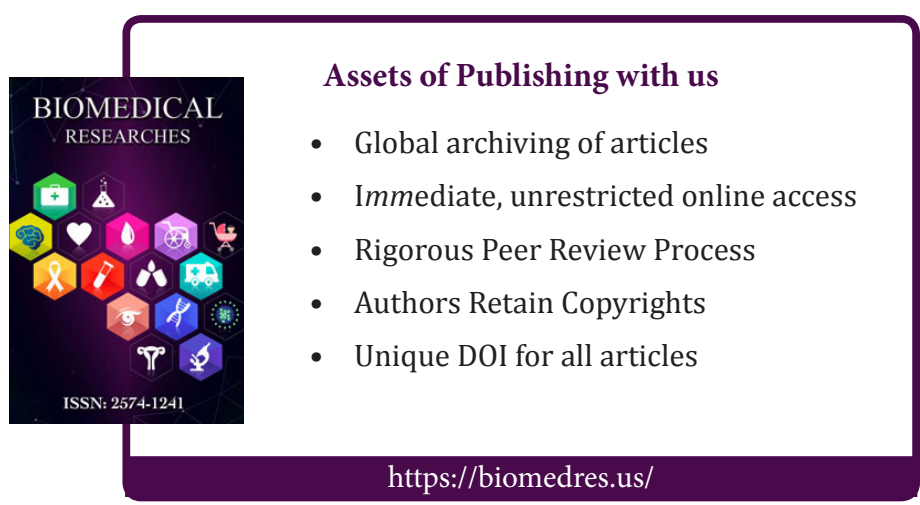

